\title{
Using Peer Mentoring to Enhance Student Experience and Increase Reten- tion in Mechanical Engineering
}

\section{Mr. Nicolas N. Brown, University of Utah}

Nicolas is a senior in the mechanical engineering department at the University of Utah. He is the peer mentoring coordinator for the Department of Mechanical Engineering, as well as an Undergraduate Research Assistant for the Ergonomics and Safety Lab. His current area of research involves designing and integrating control systems on recreational equipment for high-level spinal cord injury patients. Nicolas' senior design project is the Rodent Tracker; a mechatronics solution for managing wiring harnesses of laboratory rodents in large-scale obstacle courses.

Address: Department of Mechanical Engineering, University of Utah, 1495 East 100 South, 1550 MEK, Salt Lake City, UT 84112 Phone: 801-808-3571 Email: nicolas.n.brown@ gmail.com

\section{Ms. Joy Velarde, University of Utah}

Joy Velarde is an Academic Advisor in the Department of Mechanical Engineering at the University of Utah. She has a Bachelor of Science degree in Psychology from Brigham Young University and a Master of Arts degree in Higher Education Administration from Boston College.

\section{Dr. Debra J. Mascaro, University of Utah}

Debra J. Mascaro is the Director of Undergraduate Studies in Mechanical Engineering at the University of Utah. She holds a B.A. in Physics from Gustavus Adolphus College in St. Peter, MN, and a Ph.D. in Materials Science and Engineering from the Massachusetts Institute of Technology. She primarily teaches freshman design and programming courses. 


\title{
Using Peer Mentoring to Enhance Student Experience and Increase Retention in Mechanical Engineering
}

\begin{abstract}
This work in progress describes a new peer mentor program for first-year mechanical engineering students at the University of Utah. The program was initiated to help address the high attrition rate in the major, which is on par with the national average of $40-50 \%$. It is expected that the peer mentor program will impact retention by creating a sense of belonging in the department and at the university.

Peer mentor programs have been shown to increase both (1) levels of student success during the transition to higher education and (2) the likelihood of students identifying with the university community. In an effort to help new students feel included, the Department of Mechanical Engineering at the University of Utah has implemented a peer mentor program to serve all students new to the major, including incoming first-year and transfer students. The program distinguishes itself from similar peer mentor programs in several ways. First, the program is administered by the mechanical engineering department and services only mechanical engineering students. Second, the peer mentor program is an "opt-out” program, with all students new to the mechanical engineering department assigned a peer mentor before their first semester in the program. Third, peer mentors are recruited on a volunteer basis. Lastly, efforts were made to pair mentors and students based on common demographics and interests.

The peer mentor program has had some success so far based on the limited quantitative and qualitative data available. Results show an improvement in retention in the first-year, which is one of the primary goals of the program. Survey results indicate that mentors were most effective in sharing knowledge about resources and inspiring mentees to continue in the program. Anecdotally and from responses to open-ended survey questions, students appreciate that the program exists, but may not have felt a need to connect with their mentor during the first semester. More data are needed to determine the long-term benefits of the program, but initial indications suggest this program is beneficial and will continue beyond the current academic year.
\end{abstract}

\section{Introduction and Background}

This work in progress describes a new peer mentor program for first-year mechanical engineering students at the University of Utah. The Department of Mechanical Engineering is the second largest department within the College of Engineering, with about 900 undergraduate students declared in the major. The peer mentor program was initiated to address the high attrition rate in the major, which is on par with the national average of 40-50\%, including students who drop out of college or change majors. ${ }^{1}$ The top three reasons students will leave an engineering-based discipline in the first year of study are: (1) the perceived lack of belonging in an engineering program, (2) issues related to difficulty of curriculum, and (3) poor teaching or advising. $^{2}$ 
In multiple studies, peer mentor programs have been shown to increase both levels of student success during the transition to higher education and the likelihood of students identifying with the university. ${ }^{3}$ In an effort to help new students feel included, the Department of Mechanical Engineering at the University of Utah has implemented a peer mentor program to serve all students new to the major, including incoming first-year and transfer students. This paper will focus on first-year students.

This program distinguishes itself from similar peer mentor programs in the following ways: (1) the program is administered by the mechanical engineering department and services only mechanical engineering students to allow for major-specific focus and unity between the peer mentors and their mentees; (2) the peer mentor program is an "opt-out" program, with all students new to the mechanical engineering department assigned a peer mentor before their first semester in the program; (3) peer mentors are recruited on a volunteer basis; and (4) efforts were made to match mentors and students based on common demographics and interests. The peer mentor program is expected to positively impact retention and create a sense of belonging within the department by having experienced students guide and encourage new students during their critical first year in the program.

\section{Program Description}

Due to the many potential benefits of peer mentor programs, as described in the introduction, these types of programs are becoming more prevalent in higher education. ${ }^{3}$ The structure of the numerous programs in existence varies widely in size, scope, and goals. The short and long-term goals of the program described in this paper include: providing a sense of belonging within the department and the greater university community; increasing student retention within the major; improving student completion and graduation rates within the major; and supporting student success. This program is unique in several ways, including the program administration, organization, recruitment of volunteers, and matching of students with mentors, which will be described in more detail below.

\section{Program Administration}

The peer mentor program is administered at the department level, and focuses only on students in the mechanical engineering program. Some programs on the same campus and at other institutions include students from many different majors, who may or may not be assigned a mentor from the same major. This department's internal approach allows for a major-specific focus and a higher degree of connection and rapport between mentors and mentees. For example, the mentors can easily relate to situations that mentees are going through, as they have most likely had similar experiences with specific courses and/or professors. The mentors are also familiar with faculty, staff, and administrators within the department, so can easily direct mentees to appropriate resources. Focusing on students in one major also allows the administration of the program to flow more smoothly, as peer mentor events and mentor/mentee interactions can easily be coordinated with department events. 


\section{Program Organization}

In order to reach as many students as possible, peer mentors are assigned to every new student in the mechanical engineering program. Students who do not wish to participate may opt out at any time. This varies from other programs that are strictly "opt-in,” where students must proactively request to be paired with a mentor. The advantage to assigning all new students a mentor is that students who do not feel comfortable asking for help, or who do not initially perceive a need for mentoring, have ready access to a mentor when a need arises.

\section{Mentor Recruitment and Benefits}

Peer mentors are recruited on a volunteer basis and are unpaid, which is different from some other programs that may provide a salary, stipend, or other financial compensation. The peer mentor program uses forms of non-monetary compensation and benefits, such as mentor-specific training and access to exclusive events and activities. For example, the mentors benefited from a private resume workshop presented by Career Services in the week leading up to the Engineering Career Fair. Some social activities (e.g., pizza or dessert socials) brought the mentors together to share their thoughts and experiences with the program, while others (e.g., bowling and bubble ball soccer) provided an opportunity for the mentors to spend time with their mentees. In addition, inherent benefits of being a peer mentor include enhancing one's resume, gaining leadership skills, networking with other mentors as well as mentees, and feeling good about helping others, all of which are relied upon as forms of compensation., ${ }^{4,5}$

\section{Mentor Matching}

In any given first-year cohort in this mechanical engineering program, as few as $40 \%$ of the students are starting the program immediately out of high school. For example, students who are new to the program may have been taking prerequisites or pursuing a different major at the university, completing general education requirements at a local community college, or taking time off between high school and college for religious or other reasons. Because of this diversity in age and educational experiences, efforts were made to match mentors and new students based on common demographics and interests. This was accomplished by asking both new students and mentors to complete an online survey. Mentees who did not complete the survey were randomly matched with a mentor. This approach to mentor/mentee matching - which considers multiple factors as much as is possible - is different than that of many other programs where students are randomly assigned a mentor or paired based on a single factor, such as gender or major.

\section{Program Structure}

\section{Peer Mentor Coordinator}

To help manage the peer mentor program, a peer mentor coordinator was hired by the department. In addition to serving as a mentor, the coordinator is responsible for recruiting and training mentors, assigning mentors to mentees, assisting in setting up events, and ensuring that mentees are contacted in a consistent and timely manner. For example, the peer mentor coordinator emails the mentors on a bi-weekly basis to remind them about mentee contact deadlines, pass on information from the advising office, or inform them of upcoming events. The peer mentor coordinator is a student in the department. This student reports directly to the 
program Academic Advisor, and is overseen by the Director of Undergraduate Studies. The peer mentor coordinator is the only mentor receiving financial compensation for his/her efforts.

\section{Mentor Recruitment and Selection}

A call for peer mentors was put out to mechanical engineering juniors and seniors during the summer of 2015 via an email announcement and online application. Additional mentors were recruited by the Peer Mentor Coordinator. In addition to the online application, potential mentors were interviewed by the program Academic Advisor and the Peer Mentor Coordinator. In selecting the mentors, factors such as grade point average, extracurricular, volunteer and leadership activities, family situation, and demographics (e.g., gender and race) were considered in order to assemble a diverse group of mentors. The selected mentors encompass a wide range of demographics, including veteran, international, women, men, honors, fraternity/sorority, and LGBTQ students.

\section{Mentor Matching}

As mentioned above, one unique aspect of this peer mentor program is that new students are matched with mentors of similar backgrounds, interests and experiences. In August 2015, new students were asked to fill out an optional survey to assist in matching the students with mentors. The survey questions mirrored those asked on the mentor application. Students that responded to the survey indicating they would like to be assigned to a mentor based on the information provided were grouped accordingly. Students that did not respond to the survey or did not want the information used were randomly assigned to a mentor.

Mentors were assigned 6-12 first-year students, depending on the availability and willingness of the mentor. Based on the assumption that students who completed the survey would be more likely to respond to communication from a peer mentor, mentors were generally assigned more mentees if the pairing was random.

\section{Mentor Expectations}

Peer mentors are not counselors, academic advisors, or tutors. Their role is to help new mechanical engineering students acclimate to the major and to university life in general, and to make them feel welcome in the department and major. This includes informing mentees of campus resources, helping mentees network with peers, introducing mentees to sub-disciplines of engineering, and helping mentees build a sense of community with their fellow students. Mentors are expected to contact their mentees at the beginning of the semester, prior to midterm and final exams, and at other times throughout the semester, as deemed necessary. Communication was often via email or text messaging, but in-person contact was highly encouraged. The mentors were also expected to keep notes regarding interactions with mentees. Mentors were instructed to direct students to appropriate resources for any issues beyond the scope of their responsibilities as mentors.

\section{Mentor Training}

Peer mentors were provided training prior to the beginning of the fall semester. The purpose of the training was to (1) explain the expectations of a mentor, including expected frequency of 
contact with mentees, (2) familiarize mentors with programs and services offered on campus, (3) introduce the mentors to one another, and (4) review the Peer Mentor Handbook, which is a resource manual that outlines expectations and summarizes available resources. Additionally, representatives from the university Counseling Center, Student Success Advocates, and Career Services gave short presentations about services available to students through their respective programs.

\section{Mentor/Mentee Social Events}

Several events were held during the Fall 2015 and Spring 2016 semesters that allowed mentors and mentees to make face-to-face contact in a social setting. A fall semester kick-off barbecue provided the first formal opportunity for mentees to connect with their mentors in person. The barbecue also gave students a chance to mingle with faculty and staff. A similar event was held at the beginning of the spring semester. Donuts and hot chocolate were served, and new students starting in the spring semester were able to meet their mentors for the first time. Other events such as bowling and bubble ball soccer were held in the middle of each semester, with the intention of creating and strengthening relationships outside of the academic environment.

\section{Assessment}

\section{Program Success}

Because the peer mentor program is in the first year of implementation and not a lot of data is available, program success will primarily be determined by comparing retention data from the two prior academic years to data from the current academic year. In addition, student survey results will also be considered when evaluating the success of the program.

Retention data were compiled by comparing the number of newly-admitted students who were enrolled in the first introductory-level core mechanical engineering course in the fall to the number of those students who successfully progressed to the second introductory-level core mechanical engineering course in the spring. The reasons that students left the program were also considered and compared to historical data.

A voluntary student survey was sent out to mentees prior to the start of the fall semester to gauge perception of a mentor's ability to impact sense of belonging in the program, knowledge about campus resources, and desire to continue in the engineering program. A similar survey was administered at the end of the fall semester to assess effectiveness of the program at that point in time. Mentees were also asked to share stories and examples of how the program impacted them as well as general comments and suggestions about the program.

\section{Retention Data}

The engineering program follows a core-sequence progression of courses. Enrollment in the first-year core courses was used to determine retention and was compared with historical data. The table below shows the number of new admits who enrolled in ME EN 1000 (Introduction to Mechanical Design for Engineering Systems) in the fall, the number of those students who successfully progressed to ME EN 1010 (Computer-Based Problem Solving for Engineering Systems) in the spring, and the percentage of first-year students retained in the program. The 
historical data was limited to the two prior academic years to minimize effects of recent changes to the first-year courses as well as differences in faculty pass/fail rates.

\begin{tabular}{|c|c|c|c|}
\hline $\begin{array}{c}\text { Academic } \\
\text { Year }\end{array}$ & $\begin{array}{c}\text { New admits } \\
\text { enrolled in } \\
\text { ME EN 1000 } \\
\text { (Fall) }\end{array}$ & $\begin{array}{c}\text { Subset } \\
\text { enrolled in } \\
\text { ME EN 1010 } \\
\text { (Spring) }\end{array}$ & RetentionRate \\
\hline $2013-2014$ & 157 & 122 & $77.7 \%$ \\
\hline $2014-2015$ & 158 & 123 & $77.8 \%$ \\
\hline $2015-2016$ & 155 & 128 & $82.6 \%$ \\
\hline
\end{tabular}

Although it appears that for both 2013-14 and 2014-15, 35 students were lost from the major, 8 (2013-14) and 5 (2014-15) are currently active in the Mechanical Engineering program. In some cases, these students did not pass ME EN 1000 or Calculus I and so were not eligible to enroll in ME EN 1010 in the spring. In other cases, the students took a semester off or explored another major, but then returned to Mechanical Engineering. The 27 (2013-14) and 30 (2014-15) students not currently enrolled in the program apparently left the major because they did not pass ME EN 1000 and/or Calculus I (20-48\%), decided to pursue another major (37-50\%), or left the university altogether during the first year (15-30\%). Of the 27 students who appear to be lost from the major after Fall 2015, 55\% percent did not pass ME EN 1000 and/or Calculus I, 30\% appear to be pursuing a different major, and 15\% are not enrolled at the university for Spring.

\section{Survey Results}

At the beginning of the Fall 2015 semester, a survey was sent out to all new students who would be assigned a mentor. The purpose of the survey was to rate the anticipated impact that a peer mentor program would have on incoming first-year students. At the end of the semester, a similar survey was administered. Both surveys asked respondents to rate statements on a scale of $1-5$, with 1 being not helpful/not beneficial and 5 being very helpful/very beneficial. The survey results are summarized in the table on the following page.

\section{Open Ended Responses}

Responses by mentees were split regarding the overall effectiveness of the peer mentor program. Some students felt it was very helpful, while others did not feel they needed to take advantage of it. One common theme among the students was summed up in the following statement: "I like that the program exists, but I am confident in my abilities and haven't needed help, so I haven't made use of this resource.” Other students really appreciated the idea of a mentor, but the mentors did not keep up on communication as much as they should have, as evidenced by this response: "It was reassuring when I was first contacted by a peer mentor during my first semester here. However, there [sic] has not been much communication since those first couple of weeks.” Other students had positive interactions that changed how they felt about mechanical 
engineering: “I was informed about [mentor's] project demonstration on Design Day and it allowed me to attend. I am now interested in the type of application of mechanical engineering that [mentor] has done.”

Peer mentors were also surveyed to help determine the benefit of the program to the mentors and the effectiveness of the program from their point of view. Mentors who responded indicated that about $50 \%$ of the mentees assigned to them did not respond at all to their communication. This varied from mentor to mentor. Some mentors were able to get every mentee to communicate with them, while other mentors had only $10 \%$ of their mentees respond to any form of communication.

The mentors also relayed that they did not always have answers to their mentees' questions. For example, they were not likely to be able to answer questions regarding internships, resumes, international assistance, or undergraduate research positions. However, mentors were able to reach out to one another and resolve these issues and/or get back to the students within a few hours.

\begin{tabular}{|c|c|c|c|c|c|}
\hline & $\begin{array}{l}\text { How helpful } \\
\text { has having a } \\
\text { mentor been } \\
\text { in increasing } \\
\text { your sense of } \\
\text { belonging in } \\
\text { engineering? }\end{array}$ & $\begin{array}{l}\text { How helpful } \\
\text { has your } \\
\text { mentor been } \\
\text { in letting you } \\
\text { know about } \\
\text { campus } \\
\text { resources? }\end{array}$ & $\begin{array}{l}\text { How helpful } \\
\text { has your } \\
\text { mentor been } \\
\text { in inspiring } \\
\text { you to } \\
\text { continue to } \\
\text { pursue } \\
\text { engineering? }\end{array}$ & $\begin{array}{l}\text { How much } \\
\text { personal } \\
\text { contact have } \\
\text { you had with } \\
\text { your peer } \\
\text { mentor? }\end{array}$ & $\begin{array}{l}\text { How } \\
\text { beneficial has } \\
\text { having a peer } \\
\text { mentor been } \\
\text { in improving } \\
\text { the quality of } \\
\text { your } \\
\text { university } \\
\text { experience? }\end{array}$ \\
\hline $\begin{array}{l}\text { Pre-Sem. } \\
\text { Mean }\end{array}$ & 3.85 & 3.54 & 3.35 & 3.22 & 3.73 \\
\hline $\begin{array}{l}\text { Pre-Sem. } \\
\text { Std. Dev. }\end{array}$ & 0.90 & 0.90 & 0.99 & 0.76 & 0.86 \\
\hline Respondents & 74 & 74 & 74 & 73 & 74 \\
\hline $\begin{array}{l}\text { Post-Sem. } \\
\text { Mean }\end{array}$ & 2.54 & 3.15 & 3.08 & 2.08 & 2.23 \\
\hline $\begin{array}{l}\text { Post-Sem. } \\
\text { Std. Dev. }\end{array}$ & 1.15 & 0.86 & 1.07 & 0.83 & 0.97 \\
\hline Respondents & 13 & 13 & 13 & 13 & 13 \\
\hline
\end{tabular}




\section{Faculty and Administration Perceptions}

The peer mentor program has been perceived positively within the Department of Mechanical Engineering and the College of Engineering at the University of Utah. Professors have stated that such a program helps bring the student body closer together, which provides many benefits to the department as a whole, including the perception that the department cares about its students and is doing things to facilitate their success. The Dean of the College of Engineering has expressed interest in using this program as a template and standard of best practice for every department in the College. Advisors appreciate that a group of upper-division students are available to assist lower-division students with specific questions that they may not have the answers to because they themselves have not been through the program.

\section{Discussion}

\section{Retention}

A $4.8 \%$ increase in retention for $2015-16$ is seen compared to the two previous academic years. This represents approximately seven additional students retained. Although other factors may have contributed to this increase in retention, this initial data point is viewed as a mark of success for the peer mentor program. As this first cohort of students progresses through the program, we will continue to assess retention data - for example, how many students progress to the second and third years of the program, and how many graduate with a Bachelor of Science in Mechanical Engineering.

\section{Survey Closed-Ended Responses}

The survey results show a decrease across the board when comparing anticipated benefits of the peer mentor program at the start of the semester to perceived actual benefits at the end of the first semester. While the low post-ratings are disappointing, it should be noted that the number of respondents was low. However, the program goals may need to be better communicated to the mentees so they are more aware of what to expect.

The two questions with the smallest pre- to post-rating drop were related the level of inspiration the mentors provided to the mentees and the knowledge of the peer mentors in regards to campus resources. The latter indicates that the peer-mentor training and handbook were effective, and that the mentors were able to effectively convey information about campus resources to their mentees.

\section{Survey Open-Ended Responses}

While some of the open-ended responses from the mentees were negative, it should be noted that no students chose to opt out of the program. Students who felt that they did not need assistance from a peer mentor still chose to receive emails from their mentor.

Lack of communication by some mentors was noted in the mentee responses. Some mentors quickly became overwhelmed with their semester schedule and did not contact their mentees in a timely manner or may have initially reached out and then not made consistent contact throughout the rest of the semester. In addition to busy schedules, another factor potentially contributing to 
low communication levels is that the mentors are volunteers. Mentors would be more likely to complete their expected tasks if they were receiving monetary compensation. As volunteers, they are unlikely to perceive that their peer mentor responsibilities are more important than their own academic and/or outside commitments.

\section{Conclusions and Recommendations}

The peer mentor program has had some success based on the limited quantitative and qualitative data available. Results show an improvement in retention in the first year, which is one of the primary goals of the program. In general, survey data shows a drop between program expectations and what was actually delivered. It appears that the mentors were most effective in sharing knowledge about resources and inspiring mentees to continue in the program.

Anecdotally and from responses to survey questions, students appreciate that the program exists, but may not have felt a need to connect with their mentor during the first semester.

Changes to the peer mentor program for future semesters will focus on communication and activities that will increase the mentees' sense of belonging in the program. In addition, efforts will be made to ensure that mentors continue to communicate with mentees throughout the semester. While the barbecue and other social events were effective in connecting some students and mentees, more opportunities for face-to-face meetings would likely be beneficial. This may be facilitated by introducing the mentors during an early lecture in ME EN 1000, or by using small amounts of ME EN 1000 lab time for mentor/mentee interactions.

More data are needed to determine the long-term benefits of the program, but initial indications suggest this program is beneficial and will continue beyond the current academic year. The College of Engineering has expressed interest in implementing similar programs in the other departments in the College. It is anticipated that the experiences and results of the peer mentor program in Mechanical Engineering will be used to inspire and improve similar programs throughout the College.

\section{Bibliography}

1. Chen, X, “STEM Attrition: College Students’ Paths Into and Out of STEM Fields.” National Center for Educational Statistics, Institute of Educational Sciences, U.S. Department of Education. Retrieved 01/2016 from https://nces.ed.gov/pubsearch/pubsinfo.asp?pubid=2014001rev.

2. Marra, R. M., Shen, D., Rodgers, K., and Bogue, B., "Leaving Engineering: A Multi-Year Single Institution Study,” Journal of Engineering Education, 101(1), pp. 6-27, 2012. Retrieved 01/2016 from http://onlinelibrary.wiley.com/doi/10.1002/j.2168-9830.2012.tb00039.x/pdf.

3. Smith, T. S., Undergraduate curricular peer mentoring programs: perspectives of innovation by faculty, staff, and students, Lexington Books, Lahnham, MD (2013).

4. Hollister, L. R., “Leadership in Mentoring: The Benefits of Being a Mentor.” Retrieved 01/2016 from the American College of Healthcare Executives website: http://www.ache.org/newclub/career/MentorArticles/Benefits.cfm.

5. Huhman, H., “5 Reasons You'll Benefit from Helping a Mentee.” Retrieved 01/2016 from CNN.com: http://money.usnews.com/money/blogs/outside-voices-careers/2011/08/12/5-reasons-youll-benefit-from-helpinga-mentee. 